\title{
Wearable Flexible Sensors: A Review
}

\author{
Anindya $\mathrm{Nag}^{1 *}$, Subhas Chandra Mukhopadhyay ${ }^{1}$ and Jürgen Kosel $^{2}$
}

\begin{abstract}
The paper provides a review on some of the significant research work done on wearable flexible sensors (WFS). Sensors fabricated with flexible materials have been attached to a person along with the embedded system to monitor a parameter and transfer the significant data to the monitoring unit for further analyses. The use of wearable sensors has played a quite important role to monitor physiological parameters of a person to minimize any malfunctioning happening in the body. The paper categorizes the work according to the materials used for designing the system, the network protocols and different types of activities that were being monitored. The challenges faced by the current sensing systems and future opportunities for the wearable flexible sensors regarding its market values are also briefly explained in the paper.
\end{abstract}

Keywords- Wearable flexible sensors, physiological parameter, wireless sensor network, artificial skins, strain sensors.

\section{INTRODUCTION}

The advent of sensors in the application world has revolutionized the quality of human life. Earlier what it took hours to study or monitor an event can be addressed in minutes or seconds with the help of sensing systems. The dynamic use of sensors has led to the ever growing modification of the existing sensors. They have been used for different sectors like gas sensing [1, 2], environmental monitoring [3, 4], monitoring constituents in food products like meat [5], beverages $[6,7]$, etc. to name a few. But monitoring of physiological parameters is one of the most important applications of sensors as it helps to develop a model regarding human behavior. Each attribute can be studied individually to understand the anomalies faced by a patient and can be counteracted on.

Sensors can be broadly classified into two categories, flexible [8] and non-flexible [9]. The former one is fabricated of materials which are malleable to a certain extent without changing its properties, whereas the later one is rigid and made of brittle materials. The non-flexible sensors have been developed earlier among which the sensors with silicon substrates are the most common ones. Even though these sensors find a vast field of applications, there are certain disadvantages like stiffness, intransigency, etc.

Anindya Nag and Prof. Subhas Chandra Mukhopadhyay are with Faculty of Science and Engineering, Macquarie University, Sydney, Australia. (Email: anindya1991@gmail.com, subhas.mukhopadhyay@mq.edu.au) Prof. Jürgen Kosel is with Computer Electrical and Mathematical Sciences and Engineering Division, King Abdullah University of Science and Technology, Saudi Arabia (Email: jurgen.kosel@kaust.edu.sa).
These disadvantages are prominent especially when the sensing system is associated with monitoring physiological parameters of a person or any application which involves prominent stress on the sensor, thus damaging the sensor. These results in choosing an alternate approach where the sensor can be dynamically used thus negate any inconvenience for the person or protecting the sensor from damaging while using it on a bendable object. Apart from this, low fabrication cost, light weight, better mechanical and thermal properties are some of the advantages which make the use of flexible sensors a better approach.

Wearable sensors have revolutionized the way the activities of a person are being monitored [10]. They provide the information accurately and efficiently regarding the behavior and actions of a person. In today's world, wearable sensors are used in many sectors like medical, security, communication, etc. Figure 1 shows a schematic of a monitoring system to sensing the physiological parameters like heart rate and respiratory rate of a person and transmit the data wirelessly to the cloud via any information gateway [11]. This is a quick and efficient system because any abnormality in the transmitted data can generate a notification to the healthcare or family members.

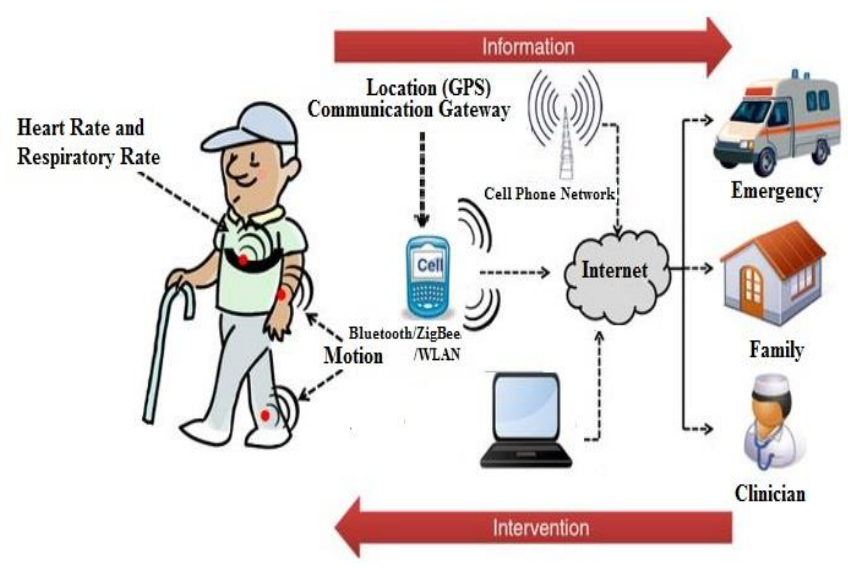

Fig. 1: Schematic representation of the use of wireless wearable sensors for physiological parameter monitoring [11].

The paper has been divided into seven sub-sections. Followed by the introduction given in section I, the materials used to fabrication wearable flexible sensors are briefly given in section II. Then, some of the standard classes of sensing types covered by wearable flexible sensors are described in section III. Then the sensor networks and the types of activities being monitored are given in section IV and $\mathrm{V}$ respectively. Finally, the challenges faced by the current systems and future opportunities of wearable flexible systems are given in 
section VI. Section VII provides the conclusion for the paper.

\section{MATERIALS FOR WEARABLE FLEXIBLE SENSORS}

The material used for fabrication of sensors is decided from some factors like the application of the sensor, its availability, total cost of manufacturing, etc. Organic electronics is one prime sector in the material side which has been substantially cultivated for the manufacture of flexible wearable devices [12]. Some of the prospects in the used of organic devices for flexible wearable devices is shown in figure 2 . These types of sensors have been used in the manufacturing of thin film transistors, ionic pumps, polymer electrodes, etc. Organic and large area electronics (OLAE) [13] is a process to develop electronic devices printed in thin layers using functional inks. The substrates used for these operations are main PET and PEN due to their transparency and lower cost compared to other organic polymers. OLAE process is currently used to develop wearable health and medical devices. Use of PDMS [14, 15], PEN [16], PI [17], P(VDF-TrFE) [18], Parylene [19] and Polypyrrole [20] have been commonly done to develop flexible sensors [21] for different applications. The electrode part of the sensor has been developed from different conducting materials like carbon-based nanomaterials and metallic nanoparticles. The carbon compounds include graphene [22-24], carbon nanotubes (CNTs) [25, 26], carbon fibers [27], etc. Among the metallic nanoparticles, silver [28, 29], gold [30, 31] and nickel [32] are some of the most commonly used ones in flexible wearable sensors.

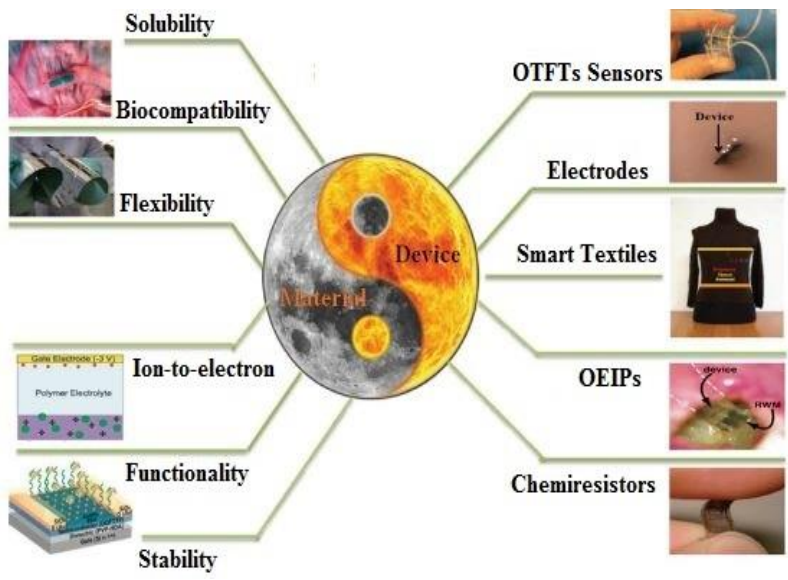

Fig. 2: Pictorial representation of the different prospects of wearable flexible devices using organic electronics [12].

There are different kinds of techniques with which the flexible sensors are developed. The dimensions of the final products dictate the procedure used to make the sensor prototype. Photolithography [33], screen-printing [34], inkjet printing [35], laser cutting [36] are some of the common ones. The raw materials used in developing these sensors depend on the applications for which the properties of the material vary. Polydimethylsiloxane (PDMS) [37],
Polyethylene terephthalate (PET) [38], Polyethylene naphthalate (PEN) [39], Polyimide (PI) [40] are some of the insulating substrates commonly used to develop flexible sensors. The difference in these polymeric materials lies in their Young's modulus, refractive index, etc. There are some conductive polymers like poly(3,4ethylenedioxythiophene) polystyrene sulfonate (PEDOT: PSS), Polyacetylene, polyaniline are some of the examples of conducting polymers which conduct electricity due to their lower band gap compared to their insulating counterparts. These polymers are mainly used in developing solar cells, batteries; liquid crystal displays (LCDs), etc. Carbon nanotubes [41], silver [42], gold [43] and copper nanoparticles [44], are some of the materials used for fabricating the electrodes in flexible sensors. Among CNTs, different sensing devices were developed with SingleWalled Carbon Nanotubes (SWCNTs) and Multi- Walled Carbon Nanotubes (MWCNTs). These two types have been used accordingly in different based on their respective applications.

\section{TyPES OF SENSING USING WEARABLE FLEXIBLE SENSORS}

The wearable flexible sensors have been employed to various kinds of sensing in everyday life. These implementations vary with the structure and properties of the sensors. Some of the common types of sensing performed with the flexible sensors have been described in this section.

Electrochemical sensing [45] is one of the most common types of flexible sensing that has been performed over the years. The flexible sensors, with their unique chemical and electronic properties have been an excellent choice to carry out different types of biochemical sensing. Some of the common types of electrochemical sensing include monitoring of glucose [46-48], $\mathrm{pH}$ [49-52], cholesterol [53, $54]$, etc. The glucose and $\mathrm{pH}$ sensors have been developed from CNTs [55] due to their curvature sidewalls and hydrophobic nature which provides a strong interaction through $\pi$-bonding. Some of the sensors [56] have used a layer-by-layer (LBL) structure to give it a more sturdy structure. Two kinds of polymers, PDDA and PET, were used to develop the substrate. The SWCNTs, being used as electrodes, were functionalized with $-\mathrm{COOH}$ group to increase the oxidative nature of the electrodes. Along with glucose sensing, these sensors provided high sensitivity towards monitoring of $\mathrm{pH}$ between the $\mathrm{pH}$ values of 5 to 9 . Figures 3(a) and 3(b) represent the shows the flexibility and dimension of the sensor respectively.

Other type of electrochemical sensing represent the monitoring of cholesterol, which is a lipid formed in the cell membranes of animals. These types of sensors have been manufactured with both SWCNTs and MWCNTs integrated with sol-gels [57]. LBL method has also been employed with the structuring of these sensors to integrate assemble different materials in a compact way [58]. So, these types of sensors have been developed with techniques like screenprinting [59], spin-coating [60], where a separate membrane 
of enzymes like cholesterol esterase [59], cholesterol oxidase [61] had been immobilized on the sensing surface.

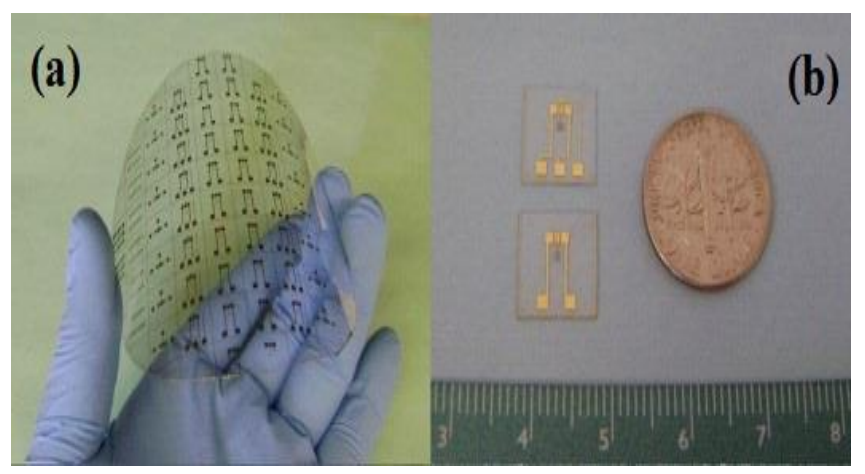

Fig. 3: Glucose/pH sensors developed from PET/PDDA and CNTs. (a) Sensors subjected to bending to show their flexibility. (b) Comparison of the size of an individual sensor to a coin to represent its dimension [56].

Pressure [62, 63] and strain [64, 65] sensors are one of the most standardized applications of flexible sensors. Different kinds of piezoresistive and piezoelectric sensors have been developed till date to monitor various physiological parameters by using them as bandages, gloves, etc. [66]. Figure 4 shows one such type formed from vertically aligned SWCNTs and PDMS as electrodes and substrate respectively. These types of sensors vary regarding gauge factor (GF) and \% of the tensile and compressive strain they can sustain without reaching the breaking point. Some of the pressure sensors [67] had been manufactured as electronic bandages where the electrodes were developed by an agglomeration of two nanoparticles. The usage of more than of conductive material allowed the sensor to be used in different mediums.

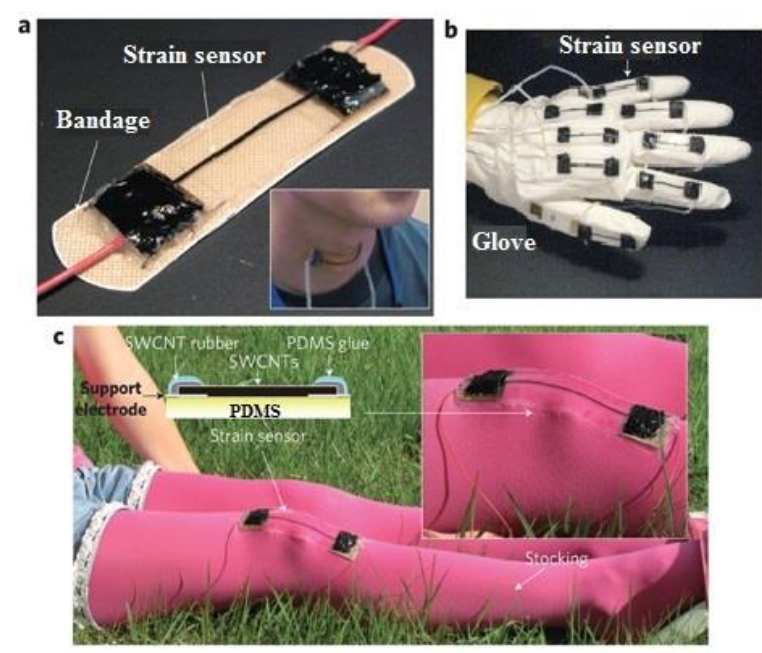

Fig. 4: Flexible and stretchable strain sensors used for physiological parameter monitoring. The sensors are fixed on a (a) bandage (b) glove, and (c) knee to determine the movement of the respective organs in terms of the change in electrical resistance [66].

These pressure sensors are also used for tactile sensing [68, 69] and artificial intelligence [21, 70]. Some of the strain sensors [71] developed and tested in the laboratory had provided a change in conductivity up to a strain of $300 \%$ having a GF of 50. These sensors were based on a nanocomposite of polyurethane (TPU) and MWCNTs with nano-fibrillated cellulose (NFC) as fillers.

Biomedical signal monitoring is another sector which has been worked up with wearable flexible electronic devices [72]. Monitoring of metabolites on the skin was done by sensors with ion-electron potentiometric transducers developed from SWCNTs [73]. Oppositely charged multilayered films of MWCNTs were used to establish chemoresistive sensors [74]. The detection of sodium $\left(\mathrm{Na}^{+}\right)$and potassium $\left(\mathrm{K}^{+}\right)$ions was detected using a sensor designed with $\mathrm{Cu} / \mathrm{PI}$ flexible electronic layer attached to an antenna for wireless transmission of data to an Android smartphone [75]. Monitoring of saliva for bacterial infection on tooth enamel had been done using graphene nanosensors. These sensors were connected to inductive coil antenna patterned with interdigital electrodes [76]. Flexible Organic electrochemical transistors (OECTs) are another type of sensors used for testing of saliva by converting biochemical signals to electrical signals. They are developed with a PANI/Nafion - graphene bilayer film [77]. These transistors were also developed by the lamination of polypropylene films and amorphous silicon thin-film transistors on plasmaenhanced PI substrates. These sensors were used as pressure sensors and in large area sensor skins [78].

Magnetic field sensors [79] are one category developed using inorganic functional nano-membranes with polymeric foils. A linear array of 8 sensors was formed to work on the principle of Hall Effect to achieve high bulk sensitivity. A wearable electronic nose [80] was also developed with a sensor array prepared from a nanocomposite of CNTs and PEN. Hydrogel systems along with electrophysiological sensors [81] were prepared with a spin coated and a thermally cured layer of PI on top of a layer of Poly (methyl methacrylate) (PMMA). The electrodes were formed with a bilayer of electron beam evaporated $\mathrm{Cr}$ and $\mathrm{Au}$. These fabricated devices were applied for ECG, stress-strain measurements along with other biomedical devices [82]. Interestingly, even alloys were used in WFS to develop biometric sensors [83]. Thin film thermocouples like $\mathrm{Sb}_{2} \mathrm{Te}_{3}$ and $\mathrm{Bi}_{2} \mathrm{Te}_{3}$ along with Kapton substrate were used to fabricate a low power, flexible micro-thermoelectric generator. The device is proposed to be used in Ambient Assistant Living (AAL) applications.

\section{IV.SENSOR NETWORKS FOR WEARABLE FLEXIBLE SENSORS}

Real-time applications of the monitoring of different physiological parameters are significantly dependent on the sensor network used to monitor and transfer the recorded data. After processing the received data in the analog and digital division of the signal conditioning circuit, the data is transferred from the sensor node to the monitoring unit via router for further analysis. A schematic diagram for the transmission of data from the sensor to the monitoring is shown in figure 5. The selection of a particular 
communication network depends on the cost of set-up, power consumption, the number of sensor nodes, the range of trans-reception, etc. Table 1 shows the comparison of some network protocols standardized by IEEE [84]. Among them, Bluetooth has been the most reasonable one due to its cheaper installation cost, less hardware, and high compatibility. That's why; substantial research work has been done on developing Bluetooth integrated health care systems [85-87]. Apart from the mentioned protocols in Table 1, there are some other networks with which data transmission for different biomedical flexible systems takes place. SHIMMER uses a Chipcon radio transceiver and 2.4 $\mathrm{GHz} \mathrm{Rufa}^{\mathrm{TM}}$ antenna [88]. Apart from this, there are other network remote technologies like Sun SPOT, IRIS, Mica2/MicaZ, Telos [89].

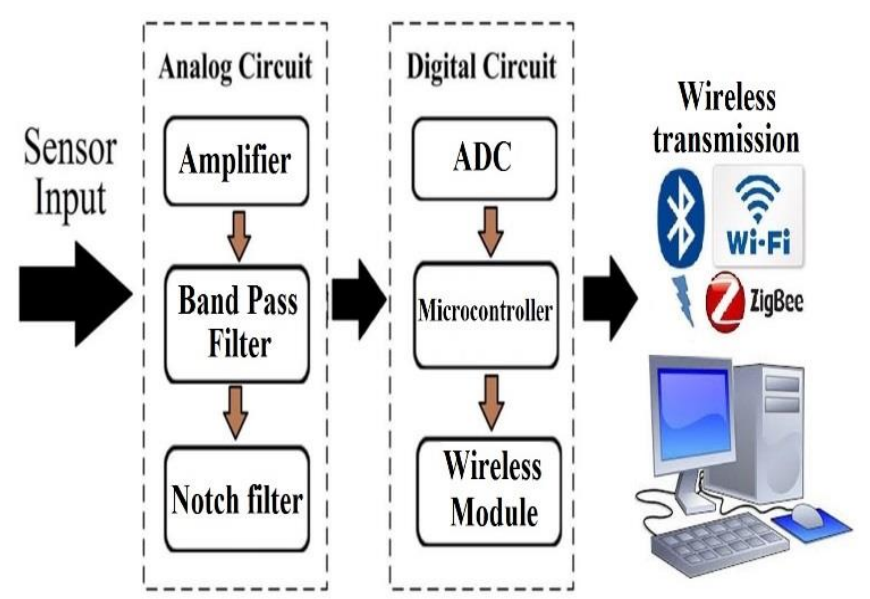

Fig. 5: Schematic diagram of the transmission of data from the sensor to the monitoring unit.

Table 1: Network protocols standardized by IEEE [84].

\begin{tabular}{|c|c|c|c|c|}
\hline Standard & $\begin{array}{c}\text { ZigBee } \\
\text { (IEEE } \\
\mathbf{8 0 2 . 1 5 . 4 )}\end{array}$ & $\begin{array}{c}\text { Bluetooth } \\
\text { (IEEE } \\
\mathbf{8 0 2 . 1 5 . 1} \\
\text { WPAN) }\end{array}$ & $\begin{array}{c}\text { Wi-Fi } \\
\text { (IEEE } \\
\mathbf{8 0 2 . 1 1} \\
\text { WLAN) }\end{array}$ & $\begin{array}{c}\text { Wi-Max } \\
\text { (IEEE } \\
\mathbf{8 0 2 . 1 1} \\
\text { WWAN) }\end{array}$ \\
\hline $\begin{array}{c}\text { Range } \\
(\mathbf{m})\end{array}$ & 100 & 10 & 5000 & 15000 \\
\hline $\begin{array}{c}\text { Data rate } \\
\text { (kbps) }\end{array}$ & $250-500$ & $1000-$ & $1000-45000$ & 75000 \\
\hline $\begin{array}{c}\text { Band- } \\
\text { width } \\
\text { (GHz) }\end{array}$ & 2.4 & 2.4 & $\begin{array}{c}2.4,3.7 \text { and } \\
5\end{array}$ & $\begin{array}{c}2.3,3.5 \\
\text { and 3.5 }\end{array}$ \\
\hline $\begin{array}{c}\text { Network } \\
\text { Topology }\end{array}$ & $\begin{array}{c}\text { Star, } \\
\text { Mesh, and } \\
\text { Cluster } \\
\text { trees }\end{array}$ & Star & $\begin{array}{c}\text { Star, Tree, } \\
\text { P2P }\end{array}$ & $\begin{array}{c}\text { Star, Tree, } \\
\text { and P2P }\end{array}$ \\
\hline $\begin{array}{c}\text { Applicati } \\
\text { ons }\end{array}$ & $\begin{array}{c}\text { Wireless } \\
\text { Sensors } \\
\text { (Monitori } \\
\text { ng and } \\
\text { Control) }\end{array}$ & $\begin{array}{c}\text { Wireless } \\
\text { Sensors } \\
\text { (Monitori } \\
\text { ng and } \\
\text { Control) }\end{array}$ & $\begin{array}{c}\text { PC based } \\
\text { Data } \\
\text { acquisition, } \\
\text { Mobile } \\
\text { Internet }\end{array}$ & $\begin{array}{c}\text { Mobile } \\
\text { Internet }\end{array}$ \\
\hline
\end{tabular}

Among these, Telos was developed by UC, Barkley which used an IEEE 802.15.4 complaint radio claiming to use onetenth of power compared to previous mote platforms [90]. Radio frequency (RF) is another network protocol which is used by different flexible acoustic resonators for data transmission [91]. For example, ECG monitoring systems have used Tmote Sky platform which has an 802.15.4 radio interface at $250 \mathrm{Kbps}$ [92]. Wireless physiological management system (WPMS) was introduced [93] which defines carrying the real-time physiological measurement data wirelessly from the medical sensors to the processing unit. The probable applications for this technique are in drug delivery systems like chemotherapy, diabetic insulin therapy, AIDS therapy [94]. The schematic diagram of the hardware architecture of the wireless sensor node for WPMS is shown in figure 6 [93].

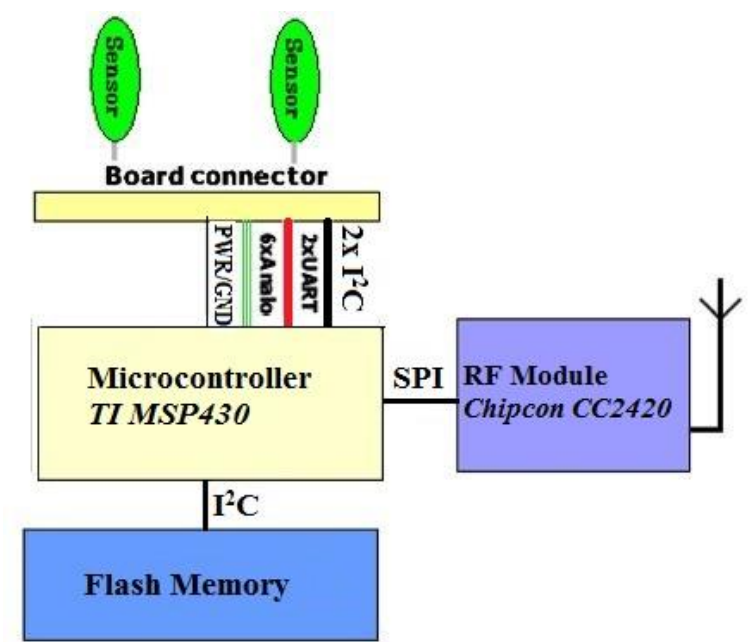

Fig. 6: Schematic diagram of the hardware architecture for the sensor node for WPMS [93].

Another network protocol called Wearable Based Sensor Networks (WBSNs), based on IEEE 802.15.4 was introduced that had different probable applications like the ECG-based system, a wearable platform for light, audio, motion and temperature sensing [95]. Toumaz Technologies, UK devised a wireless system-on-chip integrated system where the transceiver operates between 862-870 MHz and 902-928 MHz ISM bands in European and North American countries respectively [96]. Research projects with antennas and RF systems integrated into clothes have also been progressed working on Body Area Network (BAN) where the low powered devices would be surface mounted on the clothing in a fixed position [97]. BAN is categorized into three categories: off-body, onbody, and in-body [93, 98]. Battery operated systems was another option that was considered where the developed system would be powered by a battery integrated into the system [99, 100]. The advantage of using self-powered systems [101-103] is that the battery or the power unit of the wireless system does not have to be replaced every time the charging-discharging cycle gets over. 


\section{APPLICATIONS OF WEARABLE FLEXIBLE SENSORS}

Different types of flexible wearable sensors are used in the application world based on the parameter being monitored. These parameters, as a result, would decide the fabrication technique of the sensor prototypes. For example, monitoring of physiological parameters [104] of a person like limb movements [105], motions like walking, running, etc. [106], gait analysis [107] would require the sensor patches to be bigger are more flexible. But parameters like respiration [108], heart rate [109], cardiorespiratory signals [110] would require the sensors to be subtle and sensitive. Another application of WFS is as glucose sensors via different mediums like tear [111], immobilization of glucose oxidase [112, 113], etc. Electronic skins or e-skins [114, 115] are another categories which was developed to mimic the functions like that of a natural skin and determine the changes in temperature, pressure or even your health conditions. These sensors [116] are integrated with thermal actuators and organic displays. Figure 7 shows the schematic of one type of electronic skins developed with elastomeric substrates. One of the examples is the development of wearable-on-the-skin [117] sensing system that could be used as physiological sensors, non-volatile memory and for drug release [118-120] and therapeutic actuators [121, 122].

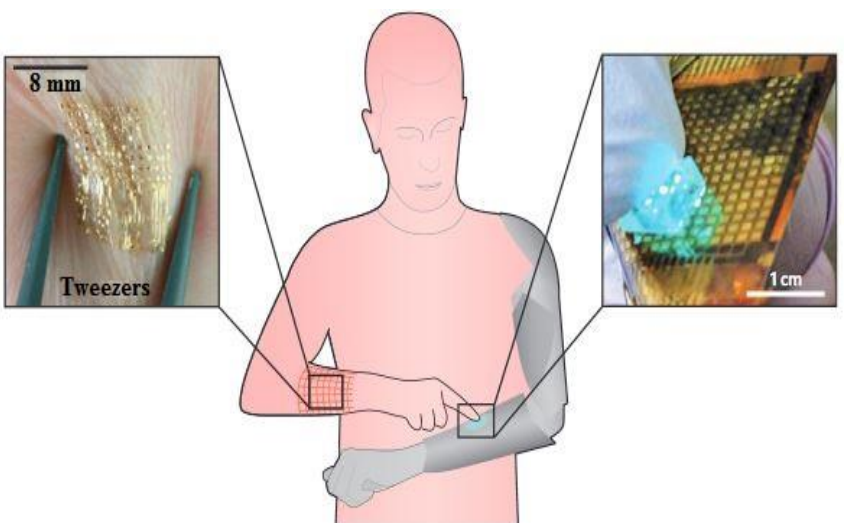

Fig. 7: Schematic diagram of the electronic skins with a sensor perception of a human arm [116].

Figure 8 shows schematic for the fabrication of the device and the finished product. Flexible sensors with high mechanical sensitivity, flexibility and durability were designed for speech recognition and physiological signals [123] in the geometry of a spider sensory system. Biomedical signal monitoring was done involving monitoring of hydration state and electrophysiological activity monitoring using Optical, electrical and radiofrequency sensors [124]. Spin-coated thin layers of PDMS and PI as substrates and bi-layers of sputtered Chromium $(\mathrm{Cr})$ and Gold $(\mathrm{Au})$ as electrodes. Monitoring of skin hydration through thermal conductivity, blood oxygenation, electrocardiogram (ECG), electromyogram (EMG), electrooculogram (EOG) are some of the suggested parameters that could be covered with these sensors. Figure
9 shows the schematic diagram of rugged and stretchable electronic sensor. Strain sensors [125-127] are the most important category of flexible sensors which have been used for multiple disciplinary applications.
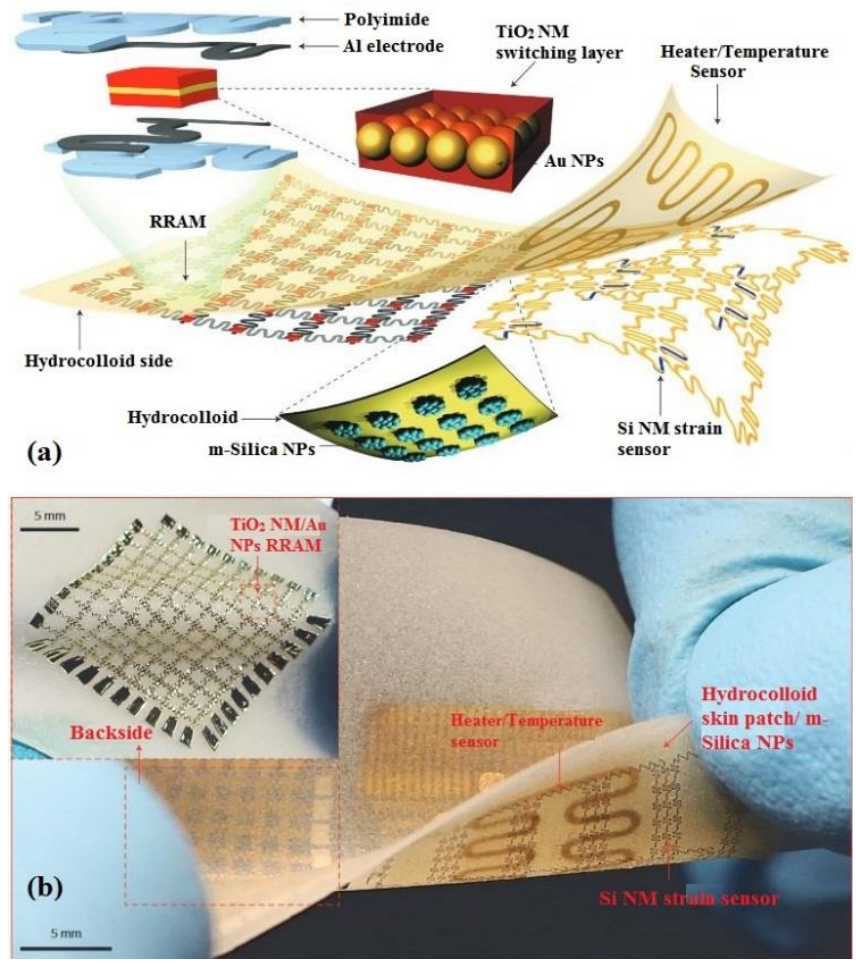

Fig. 8: (a) Schematic diagram for the materials used to develop the sensor. (b) Finished product [117].

Human motion detection [66, 128], forces and acoustic vibrations [31], artificial skins [129] are some of the other applications for those sensors. Flexible sensors have been widely used as pressure sensors $[21,31,130]$ due to their high flexibility and bendability depending on the raw material used for its fabrication. They also have great potential in the field of robotics, aviation, etc.

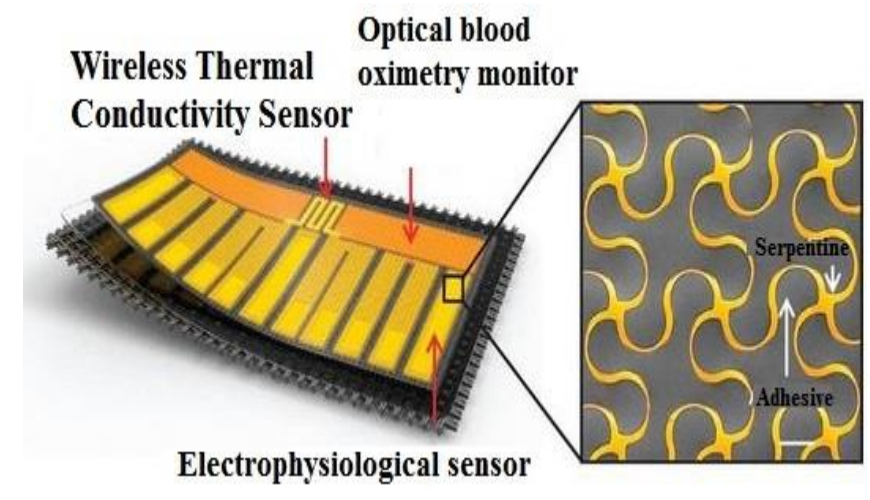

Fig. 9: Schematic diagram of the rugged and stretchable electronic sensor for electrophysiological activities [124].

Another prominent aspect of the application of WFS is the monitoring of biological fluids like sweat and saliva [131] 
via skin tattooed Nanosensors connected on the wrist and within the mouth respectively. These sensors were also used to monitor glucose electrochemically from tears of a person by embedding the wireless sensor with a contact lens. Tattoo based sensors have been widely developed [132] and used for different applications like as a potentiometric [133] and amperometric [134] sensor based systems. These devices have significant applications for skin worn silver (Ag) - zinc ( $\mathrm{Zn})$ alkaline batteries [135] and monitoring of change in $\mathrm{pH}$ [136] and ions like sodium and ammonium [137, 138].

Chemical and biological sensing also involve $\mathrm{pH}$ measurements [139] by strapping the embedded system around the waist contained with the sensor connected with microcontrollers and LED. The schematic diagram of the system and its attachment to a subject is shown in figure 10 . WFS have also been designed and experimented for detecting different kinds of gasses. Carbon monoxide (CO) and carbon dioxide $\left(\mathrm{CO}_{2}\right)$ [139] gas sensors were fitted in the garments or boots of the people like firefighters for safe measures. Oxygen $\left(\mathrm{O}_{2}\right)$ sensing systems [140, 141] were designed and mounted on the wrist of a person to determine the continuous change in oxygen level is happening in hemoglobin during respiration.

(a)

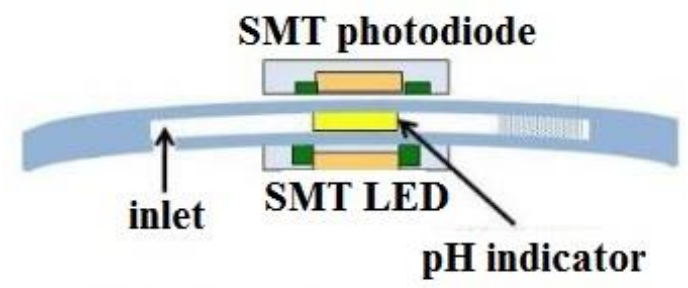

(b)

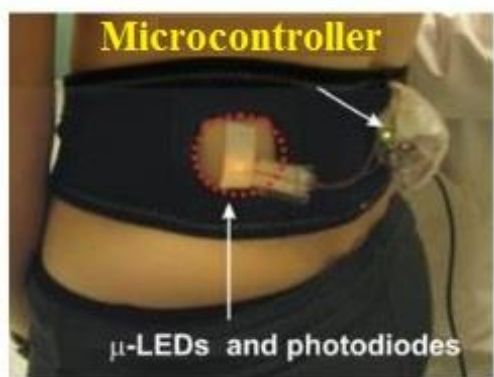

Fig. 10: (a) Schematic diagram showing the $\mathrm{pH}$ sensitive chip along with the LED and photodiode. (b) Place of the sensor on a person [139].

Microelectromechanical systems (MEMS) fabrication techniques have been primarily involved to fabrication WFS for biological applications. For example, blood cell counting sensor developed with micro silicon chips [142]. The method was also used to aid patients with hearing problems by developing microacoustic sensors for sound source localization [143] and hearing purposes [144]. It was also used to develop a wearable flexible biomedical sensor to monitor the change in temperature inside the brain during mental activities and study of circadian rhythms [145].
Textile based systems were also designed and developed for monitoring purposes. One major advantage of these systems is the comfortability of the patient being monitored without the hassle of wearing a separate wearable system. The contact of the textile with most of the skin makes it an attractive choice to attach sensors for monitoring purposes [30, 146]. Many projects like VTAMN (France), Life Shirt (USA) and Wearable Health Care Systems (WEALTHY) (Europe) are going on with different research groups with fiber based sensor systems for medicine, home health care and disease prevention [147]. Fiber based sensors were also developed primarily from piezo-resistive fibers, elastic and regular polyester fibers. These sensors were used for conducting experiments for different applications like respiration [148] and cardiovascular diseases [149].

Another category called, plastic optical fibers were used to pressure sensors [150]. Followed by the treatment with acetone to remove its stickiness, the raw flexible silicone fibers were weaved to form pressure sensors with a thickness of around $0.51 \mathrm{~mm}$. The fiber based generator [151] is one of the applications where the electrostatic charge generated in the fiber during biomechanical vibrations can be converted into electricity. These Nanogenerators work in a non-contact mode relying on air pressure [152] and thus can be used as ultrasensitive sensors for performing medical diagnostics and as measurement tools. The fiber was also integrated with computer [153], naming Planar Fashionable Circuit boards (P-FCB) for sweat monitoring using RFIP tag antennas. P-FCBs were also associated with ECG monitoring [154], physiological signal monitoring [155] and as a health monitoring system $[156,157]$. Another application to the fiber based systems is a motion sensor [158], temperature sensor [159], etc. Flexible printed circuit boards (FPCBs) were also developed for the in situ perspiration analysis [160]. The design of one of the FPCBs is shown in figure 11.

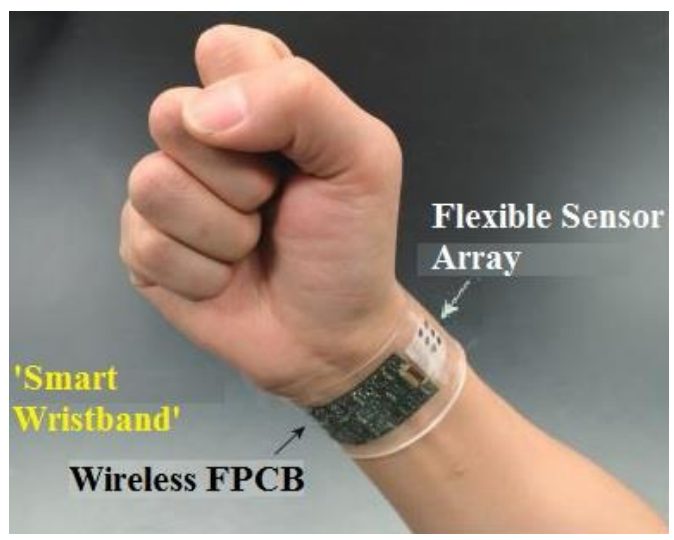

Fig. 11: Flexible Printed Circuit Board developed for in situ perspiration analysis [160].

The use of battery-operated wearable flexible sensors is another area where prominent work has been done in recent years [161, 162]. Because of the continuous need of the power for the monitoring device, flexible batteries have 
been recently developed which can be attached to the connected sensor for ubiquitous monitoring [163, 164]. Different kinds of organic materials have been utilized [165, 166] to form the electrodes in flexible lithium-ion batteries (LIBs). Graphene, CNTs, carbon cloth and cellulose are some of the materials which are used as hybrids and nanocomposites to develop flexible LIBs. Figure 12 shows the overview of the different applications of carbon-based LIBs [167]. The substrates have also be altered where lithium has been agglomerated with other substances like Sulphur [168] to achieve high power density and recycleability. To increase the dynamicity of the sensing systems, nowadays, the wearable flexible sensors are attached to the self-charging unit connected with nano-generators which would help the monitoring unit to avoid the replacement of the batteries based on their charging lifecycle [100]. Flexible batteries other than LIBs, have also been developed with different alkaline cells like $\mathrm{Zn}-\mathrm{MnO}_{2}$ [162] which was used to power various printing devices.

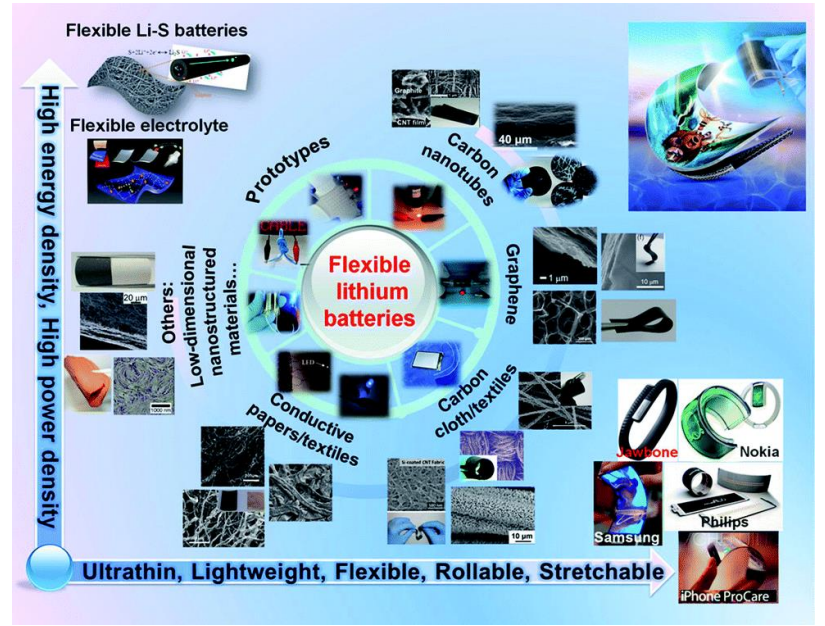

Fig. 12: An overview of different applications of carbon-based Lithium-ion Batteries (LIBs) [167].

Drug delivery pump (DDP) [169] is another phenomenon the researchers have worked upon. This DDP was developed with PDMS and a negative photoresist by standard photolithographic technique. This sensor was used as a pressure sensor where the drug can be ejected based on the applied pressure. The concept of DDP can be employed as a smart bandage along with a temperature sensor which can detect the minute changes in body temperature while doing physical activities.

The above applications have led the researchers to consider the development of wearable flexible devices that would be considered for ubiquitous health monitoring [170] as well as point-of-care (POC) [171] applications. Flexible and stretchable electronics [172, 173] have been largely used in the developing these devices. Apart from the mechanical advantages served by these flexible substrates, these devices also consume considerably much lesser power [174], which makes them a preferable choice for ubiquitous monitoring purposes. Apart from serving the dual purpose in terms of monitoring, these devices also cut shorts the problems faced due to the limited lifetime of the sensors and energy storage capabilities of the attached energy supplying devices [175]. Ubiquitous health monitoring using wearable flexible devices includes the monitoring of different physiological parameters like ECG, temperature [176] and cardiovascular problems [177]. These devices are integrated with various sensors specified for individual sensing application. One of the biggest advantages of using these wearable devices for POC applications includes rapid results which help the monitoring unit to take immediate actions. Figure 13 shows the schematic diagram of some of the wearable flexible sensors developed from different substrates, which are used for POC diagnostics [178]. These materials possess greater applications in wearable and implantable devices [179].

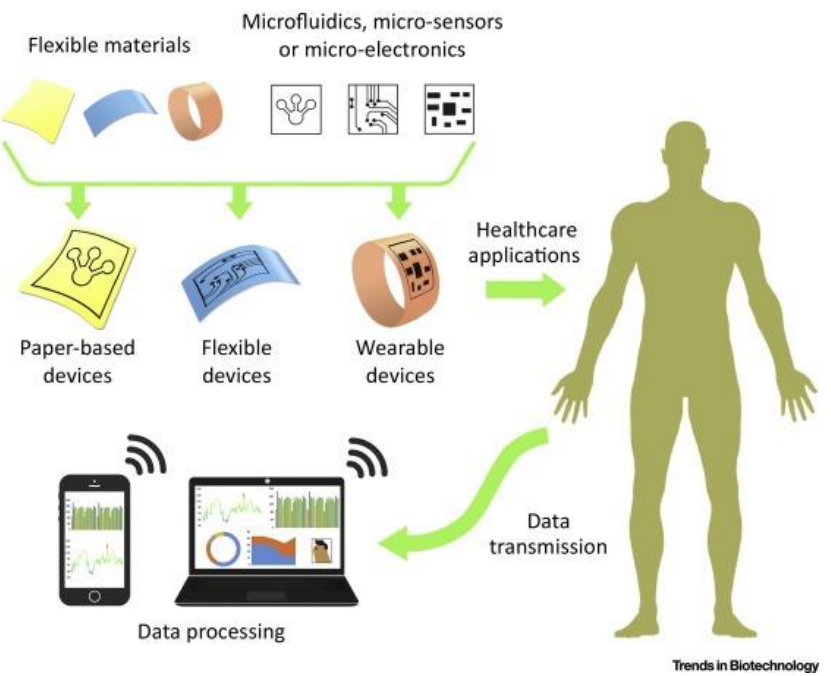

Fig. 13: Schematic diagram for the POC diagnostics using wearable flexible sensors based on different substrates [178].

\section{CHALLENGES AND FUTURE OPPORTUNITIES}

Even though a lot of work had been done with the WFS, there are still some issues that need to be dealt with. Researchers are trying 24/7 to develop sensors with better performance in terms of sensitivity and sustainability compared to the existing ones regarding fabrication and implementation for ubiquitous monitoring. The massive amount of data generated by the sensors wearable system causes a difficulty to handle and store them. Also, it becomes a tedious job for the system to filter out the significant data from the massive database for future analysis. Due to the enormous amount of monitored data, there needs to be a proper security system to curb the mishandling and misuse of the received data. Time-varying traffic is another issue caused during the data transmission from different sensor nodes in a real-time topological system. This causes a delay in data reception in the monitoring unit, thus decreasing the efficiency of the system. Also, some of the significant data might get lost due to the high traffic generated by AAL applications. The data 
transmission for a central coordinator system in Wireless Sensor Networks (WSNs) should be handled properly to minimize traffic and the loss of data. The connectivity and interoperability of the embedded system should be significant to reduce the power and data loss. From a patient's point of view, the person should not face any discomfort to wear the WFS. There should not be any breach of privacy for the patient regarding the monitoring purposes. The embedded system attached to the sensor should not loosely attach to the body or clothes worn by the person who can alter the data depending on movements and the surrounding environment. There is also a risk of thermal effects of the attached sensors caused on the tissues of the patient. A lot of factors decides the thermal effects [180] caused on the person. The number of sensors used in the embedded system should be kept as minimal as possible. The location of the sensor is also important. The position of the sensor in the arm will have more thermal effects than its position in the chest. The operating frequency of the sensor and network protocol should be as low as possible. Power consumption by WFS is another significant issue that needs to be addressed. Sensors like SHIMMER, Telos with low power consumption should be considered for monitoring purposes to reduce the overall power consumed by the WFS. The continuous supply of power to the system is another challenge that needs to be addressed for the future systems. The system should be designed for on-node processing and reduce the effects of motion artifact and distributed interference.

Printed electronics [181] is another sector which can be realized for developing future wearable flexible devices [182]. It has always been a challenge to manufacture compatible printed devices with a high throughput. The reduction in the production cost of the sensor, being one of the main motives, the idea of using abundant cheap materials to develop intelligent, smart sensors by simple printing processes is always intriguing [183]. Some of the other factors that are considered while developing printed electronics include scalable, environmentally friendly and mechanically enhanced devices. The mass production of low-cost materials like plastics and organic substrates would also lead to a wider range of applications [184]. For example, the concept of quantum dots, where the semiconducting nanocrystals were tuned for the emission of light based on their resonating wavelength, had been exploited to develop three-dimensional (3D) printed light emitting diodes (LEDs) [185]. The use of printed electronics as wearable sensors has been conceptualized for a while now [186]. Because of their high malleability, these printed devices can be easily attached to skins or textiles for monitoring purposes. Figure 14 shows the schematic of possible applications of printed electronics in the near future [187]. It depicts the use of smart sensors in also every application in day to day living. Some of the other common applications of printed electronics is in RFID tags [188], tactile sensing [189], and smart sensing [190].

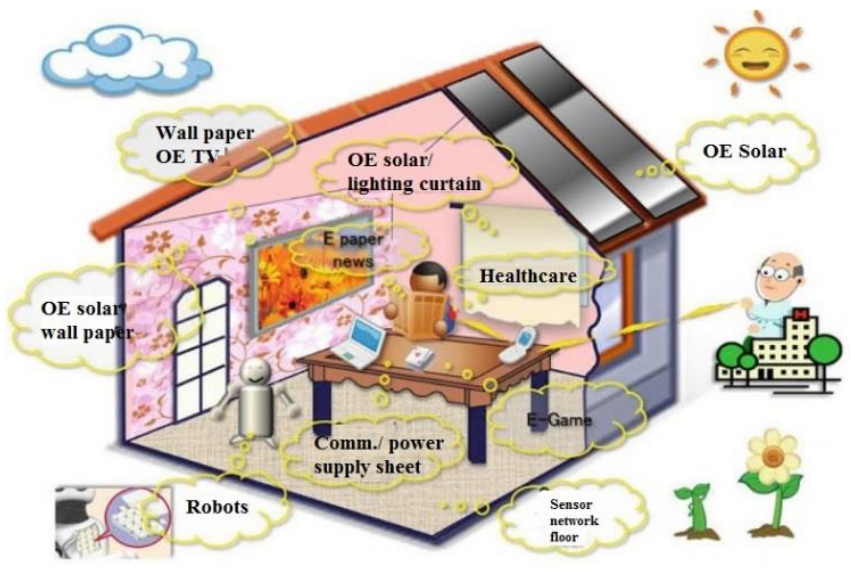

Fig. 14: Schematic of the use of printed electronics in day-to-day applications in the near future [187].

There is a prominent future of flexible electronics in wearable systems regarding its market values [191]. The market value of printed and flexible electronics is estimated to be over 75 billion USD by 2025 [192]. There is a substantial opportunity to use these flexible systems for monitoring health parameters. The estimated cost of WFS by 2020 is more than 3 billion USD [193] and over 40 billion USD with more than 240 million annual unit shipments by 2025 [194]. The challenge for the companies is to design the systems to decrease the overall fabrication cost of the systems. One way to achieve this is to consider cheap, safe and biocompatible materials for the design purposes. FlexEnable, one of the UK-based companies, has predicted the rise in organic electronics among the WFS [195]. With growing interest of the consumers, the companies should design their systems which would serve the people not only for the application purposes but also with their economic condition. The systems should be made cost-effective so that it can address the wider community in the society.

\section{CONCLUSION}

A brief review on some of the prominent research works done on WFS had been depicted in the paper. The sensor types based on different materials along with the communication networks used for monitoring purposes are described in the article. The scope of research work on this topic is increasing every day with the growth in its market value. The estimated figures for the use for WFS for the next 10-15 years have been mentioned along with the challenges that the WFS is producing companies needs to address. The growth in MEMS along with Nanoelectromechanical (NEMS) technology is expected to reduce the cost of fabrication of the flexible sensing systems leading to a wider range of applications in recent future. The utilization of the existing manufacturing techniques along with upcoming ones will assist in developing new sensing systems should avail the people to have a better quality of life in near future. 


\section{REFERENCES}

A. Nag, A. I. Zia, X. Li et al., "Novel Sensing Approach for LPG Leakage Detection: Part I-Operating Mechanism and Preliminary Results," IEEE Sensors Journal, vol. 16, no. 4, pp. 996-1003, 2016.

A. Nag, A. I. Zia, X. Li et al., "Novel Sensing Approach for LPG Leakage Detection-Part II: Effects of Particle Size, Composition, and Coating Layer Thickness," IEEE Sensors Journal, vol. 16, no. 4, pp. 1088-1094, 2016.

N. Suryadevara, S. Mukhopadhyay, R. Rayudu et al., "Sensor data fusion to determine wellness of an elderly in intelligent home monitoring environment." pp. 947-952.

M. A. M. Yunus, and S. C. Mukhopadhyay, "Development of planar electromagnetic sensors for measurement and monitoring of environmental parameters," Measurement Science and Technology, vol. 22, no. 2, pp. 025107, 2011.

S. C. Mukhopadhyay, and C. P. Gooneratne, "A novel planartype biosensor for noninvasive meat inspection," Sensors Journal, IEEE, vol. 7, no. 9, pp. 1340-1346, 2007.

A. I. Zia, S. Mukhopadhyay, I. Al-Bahadly et al., "Introducing molecular selectivity in rapid impedimetric sensing of phthalates." pp. 838-843.

A. I. Zia, M. S. A. Rahman, S. C. Mukhopadhyay et al., "Technique for rapid detection of phthalates in water and beverages," Journal of Food Engineering, vol. 116, no. 2, pp. 515-523, 2013.

M. Segev-Bar, and H. Haick, "Flexible sensors based on nanoparticles," ACS nano, vol. 7, no. 10, pp. 8366-8378, 2013.

Y. Unno, A. Affolder, P. Allport et al., "Development of n-on-p silicon sensors for very high radiation environments," Nuclear Instruments and Methods in Physics Research Section A: Accelerators, Spectrometers, Detectors and Associated Equipment, vol. 636, no. 1, pp. S24-S30, 2011.

S. C. Mukhopadhyay, "Wearable sensors for human activity monitoring: A review," IEEE Sensors Journal, vol. 15, no. 3, pp. 1321-1330, 2015.

S. Patel, H. Park, P. Bonato et al., "A review of wearable sensors and systems with application in rehabilitation," Journal of neuroengineering and rehabilitation, vol. 9, no. 1, pp. 1, 2012.

C. Liao, M. Zhang, M. Y. Yao et al., "Flexible organic electronics in biology: materials and devices," Advanced Materials, vol. 27, no. 46, pp. 7493-7527, 2015.

J. van den Brand, M. de Kok, M. Koetse et al., "Flexible and stretchable electronics for wearable health devices," Solid-State Electronics, vol. 113, pp. 116-120, 2015.

C.-Y. Chen, C.-L. Chang, T.-F. Chien et al., "Flexible PDMS electrode for one-point wearable wireless bio-potential acquisition," Sensors and Actuators A: Physical, vol. 203, pp. 20-28, 2013

J.-H. Moon, D. H. Baek, Y. Y. Choi et al., "Wearable polyimide-PDMS electrodes for intrabody communication," Journal of Micromechanics and Microengineering, vol. 20, no. 2, pp. 025032, 2010.

T. Someya, and T. Sekitani, "Bionic skins using flexible organic devices." pp. 68-71.

Y. Qin, Q. Peng, Y. Ding et al., "Lightweight, superelastic, and mechanically flexible graphene/polyimide nanocomposite foam for strain sensor application," ACS nano, vol. 9, no. 9, pp. 89338941, 2015.

T. Fujita, S. Shiono, K. Kanda et al., "Flexible sensor for human monitoring system by using $\mathrm{P}$ (VDF/TrFE) thin film." pp. 7579.

D. Ha, W. N. de Vries, S. W. John et al., "Polymer-based miniature flexible capacitive pressure sensor for intraocular pressure (IOP) monitoring inside a mouse eye," Biomedical microdevices, vol. 14, no. 1, pp. 207-215, 2012.

A. P. Tjahyono, K. C. Aw, H. Devaraj et al., "A five-fingered hand exoskeleton driven by pneumatic artificial muscles with novel polypyrrole sensors," Industrial Robot: An International Journal, vol. 40, no. 3, pp. 251-260, 2013.
Y. Zang, F. Zhang, C.-a. Di et al., "Advances of flexible pressure sensors toward artificial intelligence and health care applications," Materials Horizons, vol. 2, no. 2, pp. 140-156, 2015.

[22] S.-H. Bae, Y. Lee, B. K. Sharma et al., "Graphene-based transparent strain sensor," Carbon, vol. 51, pp. 236-242, 2013.

[23] H. Tian, Y. Shu, Y.-L. Cui et al., "Scalable fabrication of highperformance and flexible graphene strain sensors," Nanoscale, vol. 6, no. 2, pp. 699-705, 2014.

[24] K. K. Sadasivuni, A. Kafy, L. Zhai et al., "Transparent and flexible cellulose nanocrystal/reduced graphene oxide film for proximity sensing," Small, vol. 11, no. 8, pp. 994-1002, 2015.

[25] B. S. Shim, W. Chen, C. Doty et al., "Smart electronic yarns and wearable fabrics for human biomonitoring made by carbon nanotube coating with polyelectrolytes," Nano Letters, vol. 8, no. 12, pp. 4151-4157, 2008.

[26] D. J. Cohen, D. Mitra, K. Peterson et al., "A highly elastic, capacitive strain gauge based on percolating nanotube networks," Nano Letters, vol. 12, no. 4, pp. 1821-1825, 2012.

K. Jost, D. Stenger, C. R. Perez et al. "Knitted and screen printed carbon-fiber supercapacitors for applications in wearable electronics," Energy \& Environmental Science, vol. 6, no. 9, pp. 2698-2705, 2013.

[28] M. Amjadi, A. Pichitpajongkit, S. Lee et al., "Highly stretchable and sensitive strain sensor based on silver nanowire-elastomer nanocomposite," ACS nano, vol. 8, no. 5, pp. 5154-5163, 2014.

[29] J. Wang, J. Jiu, M. Nogi et al., "A highly sensitive and flexible pressure sensor with electrodes and elastomeric interlayer containing silver nanowires," Nanoscale, vol. 7, no. 7, pp. 29262932, 2015.

[30] Y. Hasegawa, M. Shikida, D. Ogura et al., "Fabrication of a wearable fabric tactile sensor produced by artificial hollow fiber," Journal of Micromechanics and Microengineering, vol. 18, no. 8, pp. 085014, 2008.

[31] S. Gong, W. Schwalb, Y. Wang et al., "A wearable and highly sensitive pressure sensor with ultrathin gold nanowires," Nature communications, vol. 5, 2014.

[32] S. L. P. Tang, "Recent developments in flexible wearable electronics for monitoring applications," Transactions of the Institute of Measurement and Control, vol. 29, no. 3-4, pp. 283300, 2007.

[33] E. F. Nuwaysir, W. Huang, T. J. Albert et al., "Gene expression analysis using oligonucleotide arrays produced by maskless photolithography," Genome research, vol. 12, no. 11, pp. 17491755, 2002.

[34] I. Locher, and G. Tröster, "Screen-printed textile transmission lines," Textile Research Journal, vol. 77, no. 11, pp. 837-842, 2007.

[35] C.-T. Wang, K.-Y. Huang, D. T. Lin et al., "A flexible proximity sensor fully fabricated by inkjet printing," Sensors, vol. 10, no. 5, pp. 5054-5062, 2010.

[36] A. J. Birnbaum, H. Kim, N. A. Charipar et al., "Laser printing of multi-layered polymer/metal heterostructures for electronic and MEMS devices," Applied Physics A: Materials Science \& Processing, vol. 99, no. 4, pp. 711-716, 2010.

[37] K. F. Lei, K.-F. Lee, and M.-Y. Lee, "Development of a flexible PDMS capacitive pressure sensor for plantar pressure measurement," Microelectronic Engineering, vol. 99, pp. 1-5, 2012.

[38] B. Hu, W. Chen, and J. Zhou, "High performance flexible sensor based on inorganic nanomaterials," Sensors and Actuators B: Chemical, vol. 176, pp. 522-533, 2013.

[39] L. Wang, J. Luo, J. Yin et al., "Flexible chemiresistor sensors: thin film assemblies of nanoparticles on a polyethylene terephthalate substrate," Journal of Materials Chemistry, vol. 20, no. 5, pp. 907-915, 2010.

[40] K.-P. Yoo, L.-T. Lim, N.-K. Min et al., "Novel resistive-type humidity sensor based on multiwall carbon nanotube/polyimide composite films," Sensors and Actuators B: Chemical, vol. 145, no. 1, pp. 120-125, 2010. 
M. F. De Volder, S. H. Tawfick, R. H. Baughman et al., "Carbon nanotubes: present and future commercial applications," Science, vol. 339, no. 6119, pp. 535-539, 2013.

[42] S. Prabhu, and E. K. Poulose, "Silver nanoparticles: mechanism of antimicrobial action, synthesis, medical applications, and toxicity effects," International Nano Letters, vol. 2, no. 1, pp. 110, 2012.

[43] K. Saha, S. S. Agasti, C. Kim et al., "Gold nanoparticles in chemical and biological sensing," Chemical reviews, vol. 112, no. 5, pp. 2739-2779, 2012.

[44] H.-J. Lee, G. Lee, N. R. Jang et al., "Biological synthesis of copper nanoparticles using plant extract," Nanotechnology, vol. 1, no. 1, pp. 371-374, 2011.

[45] Y. Shao, J. Wang, H. Wu et al., "Graphene based electrochemical sensors and biosensors: a review," Electroanalysis, vol. 22, no. 10, pp. 1027-1036, 2010.

[46] K. Wang, Q. Liu, Q.-M. Guan et al., "Enhanced direct electrochemistry of glucose oxidase and biosensing for glucose via synergy effect of graphene and CdS nanocrystals," Biosensors and Bioelectronics, vol. 26, no. 5, pp. 2252-2257, 2011.

[47] S. Alwarappan, C. Liu, A. Kumar et al., "Enzyme-doped graphene nanosheets for enhanced glucose biosensing," The Journal of Physical Chemistry C, vol. 114, no. 30, pp. 1292012924,2010

[48] J. Zhang, J. Ma, S. Zhang et al., "A highly sensitive nonenzymatic glucose sensor based on $\mathrm{CuO}$ nanoparticles decorated carbon spheres," Sensors and Actuators B: Chemical, vol. 211, pp. 385-391, 2015 .

[49] A. Maroto, K. Balasubramanian, M. Burghard et al., "Functionalized metallic carbon nanotube devices for $\mathrm{pH}$ sensing," ChemPhysChem, vol. 8, no. 2, pp. 220-223, 2007.

[50] P. Li, C. M. Martin, K. K. Yeung et al., "Dielectrophoresis aligned single-walled carbon nanotubes as $\mathrm{pH}$ sensors," Biosensors, vol. 1, no. 1, pp. 23-35, 2011.

[51] P. Gou, N. D. Kraut, I. M. Feigel et al., "Carbon nanotube chemiresistor for wireless $\mathrm{pH}$ sensing," Scientific reports, vol. 4, 2014.

[52] W.-D. Zhang, and B. Xu, "A solid-state $\mathrm{pH}$ sensor based on WO 3-modified vertically aligned multiwalled carbon nanotubes," Electrochemistry Communications, vol. 11, no. 5, pp. 1038-1041, 2009.

[53] L. Zhu, L. Xu, L. Tan et al., "Direct electrochemistry of cholesterol oxidase immobilized on gold nanoparticlesdecorated multiwalled carbon nanotubes and cholesterol sensing," Talanta, vol. 106, pp. 192-199, 2013.

[54] J. Ji, Z. Zhou, X. Zhao et al., "Electrochemical sensor based on molecularly imprinted film at Au nanoparticles-carbon nanotubes modified electrode for determination of cholesterol," Biosensors and Bioelectronics, vol. 66, pp. 590-595, 2015.

[55] A. H. Pourasl, M. T. Ahmadi, M. Rahmani et al., "Analytical modeling of glucose biosensors based on carbon nanotubes," Nanoscale research letters, vol. 9, no. 1, pp. 33, 2014.

[56] M. Kaempgen, and S. Roth, "Transparent and flexible carbon nanotube/polyaniline $\mathrm{pH}$ sensors," Journal of Electroanalytical Chemistry, vol. 586, no. 1, pp. 72-76, 2006

[57] X. Tan, M. Li, P. Cai et al., "An amperometric cholesterol biosensor based on multiwalled carbon nanotubes and organically modified sol-gel/chitosan hybrid composite film," Analytical biochemistry, vol. 337, no. 1, pp. 111-120, 2005.

[58] X. Cai, X. Gao, L. Wang et al., "A layer-by-layer assembled and carbon nanotubes/gold nanoparticles-based bienzyme biosensor for cholesterol detection," Sensors and Actuators B: Chemical, vol. 181, pp. 575-583, 2013.

[59] G. Li, J. Liao, G. Hu et al., "Study of carbon nanotube modified biosensor for monitoring total cholesterol in blood," Biosensors and Bioelectronics, vol. 20, no. 10, pp. 2140-2144, 2005.

[60] P. R. Solanki, A. Kaushik, A. A. Ansari et al., "Multi-walled carbon nanotubes/sol-gel-derived silica/chitosan nanobiocomposite for total cholesterol sensor," Sensors and Actuators B: Chemical, vol. 137, no. 2, pp. 727-735, 2009.
C. Dhand, S. K. Arya, M. Datta et al., "Polyaniline-carbon nanotube composite film for cholesterol biosensor," Analytical biochemistry, vol. 383, no. 2, pp. 194-199, 2008.

[62] J. Hwang, J. Jang, K. Hong et al., "Poly (3-hexylthiophene) wrapped carbon nanotube/poly (dimethylsiloxane) composites for use in finger-sensing piezoresistive pressure sensors," Carbon, vol. 49, no. 1, pp. 106-110, 2011.

[63] Y. Pang, H. Tian, L. Tao et al., "Flexible, Highly Sensitive, and Wearable Pressure and Strain Sensors with Graphene Porous Network Structure," ACS applied materials \& interfaces, vol. 8, no. 40, pp. 26458-26462, 2016.

[64] J. Zhou, H. Yu, X. Xu et al., "Ultrasensitive, Stretchable Strain Sensors Based on Fragmented Carbon Nanotube Papers," ACS applied materials \& interfaces, vol. 9, no. 5, pp. 4835-4842, 2017.

[65] Y. Li, Y. A. Samad, T. Taha et al., "Highly flexible strain sensor from tissue paper for wearable electronics," ACS Sustainable Chemistry \& Engineering, vol. 4, no. 8, pp. 42884295, 2016.

[66] T. Yamada, Y. Hayamizu, Y. Yamamoto et al., "A stretchable carbon nanotube strain sensor for human-motion detection," Nature nanotechnology, vol. 6, no. 5, pp. 296-301, 2011.

[67] J.-Y. Jeon, and T.-J. Ha, "Waterproof electronic-bandage with tunable sensitivity for wearable strain sensors," ACS applied materials \& interfaces, vol. 8, no. 4, pp. 2866-2871, 2016.

[68] C. Larson, B. Peele, S. Li et al., "Highly stretchable electroluminescent skin for optical signaling and tactile sensing," Science, vol. 351, no. 6277, pp. 1071-1074, 2016.

[69] S. Nakata, K. Kanao, S. Harada et al., "Flexible and high selective pressure sensitive rubber for tactile sensing." pp. 873876.

[70] M. Amjadi, K. U. Kyung, I. Park et al., "Stretchable, Skin - Mountable, and Wearable Strain Sensors and Their Potential Applications: A Review," Advanced Functional Materials, 2016.

[71] S. Xu, W. Yu, M. Jing et al., "Largely Enhanced Stretching Sensitivity of Polyurethane/CNTs Nanocomposites via Incorporation of Cellulose Nanofiber," The Journal of Physical Chemistry C, 2017.

[72] D. Vilela, A. Romeo, and S. Sánchez, "Flexible sensors for biomedical technology," Lab on a Chip, vol. 16, no. 3, pp. 402408, 2016.

[73] G. A. Zelada-Guillén, J. L. Sebastián-Avila, P. Blondeau et al., "Label-free detection of Staphylococcus aureus in skin using real-time potentiometric biosensors based on carbon nanotubes and aptamers," Biosensors and Bioelectronics, vol. 31, no. 1, pp. 226-232, 2012.

[74] K. Saetia, J. M. Schnorr, M. M. Mannarino et al., "Spray - Layer-by - Layer Carbon Nanotube/Electrospun Fiber Electrodes for Flexible Chemiresistive Sensor Applications," Advanced Functional Materials, vol. 24, no. 4, pp. 492-502, 2014.

[75] D. P. Rose, M. E. Ratterman, D. K. Griffin et al., "Adhesive RFID sensor patch for monitoring of sweat electrolytes," IEEE Transactions on Biomedical Engineering, vol. 62, no. 6, pp. 1457-1465, 2015

[76] M. S. Mannoor, H. Tao, J. D. Clayton et al., "Graphene-based wireless bacteria detection on tooth enamel," Nature communications, vol. 3, pp. 763, 2012.

[77] C. Liao, C. Mak, M. Zhang et al., "Flexible organic electrochemical transistors for highly selective enzyme biosensors and used for saliva testing," Advanced Materials, vol. 27, no. 4, pp. 676-681, 2015.

[78] I. Graz, M. Kaltenbrunner, C. Keplinger et al., "Flexible ferroelectret field-effect transistor for large-area sensor skins and microphones," Applied Physics Letters, vol. 89, no. 7, pp. 073501, 2006

[79] M. Melzer, J. I. Mönch, D. Makarov et al., "Wearable magnetic field sensors for flexible electronics," Advanced Materials, vol. 27, no. 7, pp. 1274-1280, 2015. 
[80] P. Lorwongtragool, E. Sowade, N. Watthanawisuth et al., "A novel wearable electronic nose for healthcare based on flexible printed chemical sensor array," Sensors, vol. 14, no. 10, pp. 19700-19712, 2014

[81] K.-I. Jang, H. U. Chung, S. Xu et al., "Soft network composite materials with deterministic and bio-inspired designs," Nature communications, vol. 6, 2015.

[82] J. C. Yeo, and C. T. Lim, "Emerging flexible and wearable physical sensing platforms for healthcare and biomedical applications," Microsystems \& Nanoengineering, vol. 2, pp. $16043,2016$.

[83] L. Francioso, C. De Pascali, I. Farella et al., "Flexible thermoelectric generator for wearable biometric sensors." pp. 747-750.

[84] E. Y. Song, and K. B. Lee, "IEEE 1451.5 standard-based wireless sensor networks," Advances in Wireless Sensors and Sensor Networks, pp. 243-271: Springer, 2010.

[85] J. Haartsen, "Bluetooth-The universal radio interface for ad hoc, wireless connectivity," Ericsson review, vol. 3, no. 1, pp. 110117, 1998.

[86] R. Ohmura, F. Naya, H. Noma et al., "B-pack: a bluetoothbased wearable sensing device for nursing activity recognition." p. 6 pp.

[87] M. Strauss, C. Reynolds, S. Hughes et al., "The handwave bluetooth skin conductance sensor." pp. 699-706.

[88] A. Burns, B. R. Greene, M. J. McGrath et al., "SHIMMERTM-A wireless sensor platform for noninvasive biomedical research," IEEE Sensors Journal, vol. 10, no. 9, pp. 1527-1534, 2010.

[89] M. Johnson, M. Healy, P. van de Ven et al., "A comparative review of wireless sensor network mote technologies." pp. 1439-1442.

[90] J. Polastre, R. Szewczyk, and D. Culler, "Telos: enabling ultralow power wireless research." pp. 364-369.

[91] C. Zhou, Y. Shu, Y. Yang et al., "Flexible structured highfrequency film bulk acoustic resonator for flexible wireless electronics," Journal of Micromechanics and Microengineering, vol. 25 , no. 5, pp. 055003, 2015.

[92] C. Park, P. H. Chou, Y. Bai et al., "An ultra-wearable, wireless, low power ECG monitoring system." pp. 241-244.

[93] Y. Hao, and R. Foster, "Wireless body sensor networks for health-monitoring applications," Physiological measurement, vol. 29, no. 11, pp. R27, 2008.

[94] V. Jones, N. Shashar, O. B. Shaphrut et al., "Remote monitoring for healthcare and for safety in extreme environments," $M$ Health, pp. 561-573: Springer, 2006.

[95] U. Maurer, A. Rowe, A. Smailagic et al., "eWatch: a wearable sensor and notification platform." pp. 4 pp.-145.

[96] A. C. W. Wong, G. Kathiresan, C. K. T. Chan et al., "A 1 V wireless transceiver for an ultra-low-power SoC for biotelemetry applications," IEEE Journal of Solid-State Circuits, vol. 43, no. 7, pp. 1511-1521, 2008.

[97] E. Jovanov, and A. Milenkovic, "Body area networks for ubiquitous healthcare applications: opportunities and challenges," Journal of medical systems, vol. 35 , no. 5 , pp. 1245-1254, 2011.

[98] P. S. Hall, and Y. Hao, "Antennas and propagation for bodycentric wireless networks," Norwood, MA, 2006.

[99] K. Malzahn, J. R. Windmiller, G. Valdés-Ramírez et al., "Wearable electrochemical sensors for in situ analysis in marine environments," Analyst, vol. 136, no. 14, pp. 2912-2917, 2011.

[100] X. Pu, L. Li, H. Song et al., " A Self - Charging Power Unit by Integration of a Textile Triboelectric Nanogenerator and a Flexible Lithium - Ion Battery for Wearable Electronics," Advanced Materials, vol. 27, no. 15, pp. 2472-2478, 2015.

[101] X. Xiao, T. Li, P. Yang et al., "Fiber-based all-solid-state flexible supercapacitors for self-powered systems," ACS nano, vol. 6, no. 10, pp. 9200-9206, 2012.

[102] F.-R. Fan, L. Lin, G. Zhu et al., "Transparent triboelectric nanogenerators and self-powered pressure sensors based on micropatterned plastic films," Nano Letters, vol. 12, no. 6, pp. 3109-3114, 2012.
[103] M. Ha, J. Park, Y. Lee et al., "Triboelectric generators and sensors for self-powered wearable electronics," ACS nano, vol. 9, no. 4, pp. 3421-3427, 2015

[104] W. Zeng, L. Shu, Q. Li et al., "Fiber - based wearable electronics: a review of materials, fabrication, devices, and applications," Advanced Materials, vol. 26, no. 31, pp. 53105336, 2014.

[105] A. Nag, S. C. Mukhopadhyay, and J. Kosel, "Flexible carbon nanotube nanocomposite sensor for multiple physiological parameter monitoring," Sensors and Actuators A: Physical, vol. 251, pp. 148-155, 2016.

[106] S. Yao, and Y. Zhu, "Wearable multifunctional sensors using printed stretchable conductors made of silver nanowires," Nanoscale, vol. 6, no. 4, pp. 2345-2352, 2014.

[107] W. Tao, T. Liu, R. Zheng et al., "Gait analysis using wearable sensors," Sensors, vol. 12, no. 2, pp. 2255-2283, 2012.

[108] Y. Jiang, H. Hamada, S. Shiono et al., "A PVDF-based flexible cardiorespiratory sensor with independently optimized sensitivity to heartbeat and respiration," Procedia Engineering, vol. 5, pp. 1466-1469, 2010.

[109] J. A. Patterson, D. C. Mcllwraith, and G.-Z. Yang, "A flexible, low noise reflective PPG sensor platform for ear-worn heart rate monitoring." pp. 286-291

[110] S. Choi, and Z. Jiang, "A novel wearable sensor device with conductive fabric and PVDF film for monitoring cardiorespiratory signals," Sensors and Actuators A: Physical, vol. 128, no. 2, pp. 317-326, 2006.

[111] S. Iguchi, H. Kudo, T. Saito et al., "A flexible and wearable biosensor for tear glucose measurement," Biomedical microdevices, vol. 9, no. 4, pp. 603-609, 2007.

[112] H. Kudo, T. Sawada, E. Kazawa et al., "A flexible and wearable glucose sensor based on functional polymers with Soft-MEMS techniques," Biosensors and Bioelectronics, vol. 22, no. 4, pp. 558-562, 2006.

[113] Y. H. Kwak, D. S. Choi, Y. N. Kim et al., "Flexible glucose sensor using CVD-grown graphene-based field effect transistor," Biosensors and Bioelectronics, vol. 37, no. 1, pp. 82-87, 2012.

[114] X. Wang, Y. Gu, Z. Xiong et al., "Silk - molded flexible, ultrasensitive, and highly stable electronic skin for monitoring human physiological signals," Advanced Materials, vol. 26, no. 9, pp. 1336-1342, 2014.

[115] R. B. Katragadda, and Y. Xu, "A novel intelligent textile technology based on silicon flexible skins," Sensors and Actuators A: Physical, vol. 143, no. 1, pp. 169-174, 2008.

[116] S. Bauer, "Flexible electronics: Sophisticated skin," Nature Materials, vol. 12, no. 10, pp. 871-872, 2013.

[117] D. Son, J. Lee, S. Qiao et al., "Multifunctional wearable devices for diagnosis and therapy of movement disorders," Nature nanotechnology, vol. 9, no. 5, pp. 397-404, 2014.

[118] S. Choi, J. Park, W. Hyun et al., "Stretchable heater using ligand-exchanged silver nanowire nanocomposite for wearable articular thermotherapy," ACS nano, vol. 9, no. 6, pp. 66266633,2015

[119] I. R. Minev, P. Musienko, A. Hirsch et al., "Electronic dura mater for long-term multimodal neural interfaces," Science, vol. 347, no. 6218, pp. 159-163, 2015

[120] J. Di, S. Yao, Y. Ye et al., "Stretch-triggered drug delivery from wearable elastomer films containing therapeutic depots," ACS nano, vol. 9, no. 9, pp. 9407-9415, 2015

[121] J. S. Petrofsky, M. Laymon, and H. Lee, "Effect of heat and cold on tendon flexibility and force to flex the human knee," Medical science monitor, vol. 19, pp. 661-667, 2013.

[122] J. M. Mayer, V. Mooney, L. N. Matheson et al., "Continuous low-level heat wrap therapy for the prevention and early phase treatment of delayed-onset muscle soreness of the low back: a randomized controlled trial," Archives of physical medicine and rehabilitation, vol. 87, no. 10, pp. 1310-1317, 2006.

[123] D. Kang, P. V. Pikhitsa, Y. W. Choi et al., "Ultrasensitive mechanical crack-based sensor inspired by the spider sensory system," Nature, vol. 516, no. 7530, pp. 222-226, 2014. 
[124] K.-I. Jang, S. Y. Han, S. Xu et al., "Rugged and breathable forms of stretchable electronics with adherent composite substrates for transcutaneous monitoring," Nature communications, vol. 5, 2014.

[125] Y. Wang, R. Yang, Z. Shi et al., "Super-elastic graphene ripples for flexible strain sensors," ACS nano, vol. 5, no. 5, pp. 36453650, 2011.

[126] F.-Y. Chang, R.-H. Wang, H. Yang et al., "Flexible strain sensors fabricated with carbon nano-tube and carbon nano-fiber composite thin films," Thin solid films, vol. 518, no. 24, pp. 7343-7347, 2010.

[127] X. Xiao, L. Yuan, J. Zhong et al., "High - Strain Sensors Based on $\mathrm{ZnO}$ Nanowire/Polystyrene Hybridized Flexible Films," Advanced Materials, vol. 23, no. 45, pp. 5440-5444, 2011.

[128] J. J. Park, W. J. Hyun, S. C. Mun et al., "Highly stretchable and wearable graphene strain sensors with controllable sensitivity for human motion monitoring," ACS applied materials \& interfaces, vol. 7, no. 11, pp. 6317-6324, 2015.

[129] C. Pang, G.-Y. Lee, T.-i. Kim et al., "A flexible and highly sensitive strain-gauge sensor using reversible interlocking of nanofibres," Nature Materials, vol. 11, no. 9, pp. 795-801, 2012.

[130] G. Schwartz, B. C.-K. Tee, J. Mei et al., "Flexible polymer transistors with high pressure sensitivity for application in electronic skin and health monitoring," Nature communications, vol. 4, pp. 1859, 2013.

[131] G. Matzeu, L. Florea, and D. Diamond, "Advances in wearable chemical sensor design for monitoring biological fluids," Sensors and Actuators B: Chemical, vol. 211, pp. 403-418, 2015.

[132] A. J. Bandodkar, W. Jia, and J. Wang, "Tattoo - Based Wearable Electrochemical Devices: A Review," Electroanalysis, vol. 27, no. 3, pp. 562-572, 2015.

[133] E. Bakker, E. Pretsch, and P. Bühlmann, "Selectivity of potentiometric ion sensors," Analytical chemistry, vol. 72, no. 6, pp. 1127-1133, 2000.

[134] W. Jia, A. J. Bandodkar, G. Valdés-Ramírez et al., "Electrochemical tattoo biosensors for real-time noninvasive lactate monitoring in human perspiration," Analytical chemistry, vol. 85 , no. 14, pp. 6553-6560, 2013

[135] S. Berchmans, A. J. Bandodkar, W. Jia et al., "An epidermal alkaline rechargeable $\mathrm{Ag}-\mathrm{Zn}$ printable tattoo battery for wearable electronics," Journal of Materials Chemistry A, vol. 2, no. 38 , pp. $15788-15795,2014$

[136] A. J. Bandodkar, V. W. Hung, W. Jia et al., "Tattoo-based potentiometric ion-selective sensors for epidermal $\mathrm{pH}$ monitoring," Analyst, vol. 138, no. 1, pp. 123-128, 2013.

[137] A. J. Bandodkar, D. Molinnus, O. Mirza et al., "Epidermal tattoo potentiometric sodium sensors with wireless signal transduction for continuous non-invasive sweat monitoring," Biosensors and Bioelectronics, vol. 54, pp. 603-609, 2014.

[138] T. Guinovart, A. J. Bandodkar, J. R. Windmiller et al., "A potentiometric tattoo sensor for monitoring ammonium in sweat," Analyst, vol. 138, no. 22, pp. 7031-7038, 2013.

[139] S. Coyle, F. Benito-Lopez, T. Radu et al., "Fibers and fabrics for chemical and biological sensing," Research Journal of Textile and Apparel, vol. 14, no. 4, pp. 63-72, 2010.

[140] Y. Tian, B. R. Shumway, and D. R. Meldrum, "A new crosslinkable oxygen sensor covalently bonded into poly (2hydroxyethyl methacrylate)-co-polyacrylamide thin film for dissolved oxygen sensing," Chemistry of Materials, vol. 22, no. 6, pp. 2069-2078, 2010.

[141] H. Kudo, S. Iguchi, T. Yamada et al., "A flexible transcutaneous oxygen sensor using polymer membranes," Biomedical microdevices, vol. 9, no. 1, pp. 1-6, 2007.

[142] D. Satake, H. Ebi, N. Oku et al., "A sensor for blood cell counter using MEMS technology," Sensors and Actuators B: Chemical, vol. 83, no. 1, pp. 77-81, 2002.

[143] A. Lisiewski, H. Liu, M. Yu et al., "Fly-ear inspired microsensor for sound source localization in two dimensions," The
Journal of the Acoustical Society of America, vol. 129, no. 5, pp. EL166-EL171, 2011.

[144] S. C. Ko, C.-H. Jun, W. I. Jang et al., "Micromachined air-gap structure MEMS acoustic sensor using reproducible high-speed lateral etching and CMP process," Journal of Micromechanics and Microengineering, vol. 16, no. 10, pp. 2071, 2006

[145] A. Dittmar, C. Gehin, G. Delhomme et al., "A non invasive wearable sensor for the measurement of brain temperature." pp. 900-902.

[146] I. Korhonen, J. Parkka, and M. Van Gils, "Health monitoring in the home of the future," IEEE Engineering in medicine and biology magazine, vol. 22, no. 3, pp. 66-73, 2003.

[147] F. Axisa, P. M. Schmitt, C. Gehin et al., "Flexible technologies and smart clothing for citizen medicine, home healthcare, and disease prevention," IEEE Transactions on Information Technology in Biomedicine, vol. 9, no. 3, pp. 325-336, 2005.

[148] C.-T. Huang, C.-L. Shen, C.-F. Tang et al., "A wearable yarnbased piezo-resistive sensor," Sensors and Actuators A: Physical, vol. 141, no. 2, pp. 396-403, 2008.

[149] M. Pacelli, L. Caldani, and R. Paradiso, "Textile piezoresistive sensors for biomechanical variables monitoring." pp. 53585361.

[150] M. Rothmaier, M. P. Luong, and F. Clemens, "Textile pressure sensor made of flexible plastic optical fibers," Sensors, vol. 8, no. 7, pp. 4318-4329, 2008.

[151] J. Zhong, Y. Zhang, Q. Zhong et al., "Fiber-based generator for wearable electronics and mobile medication," ACS nano, vol. 8, no. 6, pp. 6273-6280, 2014.

[152] Z. Li, and Z. L. Wang, “Air/Liquid - Pressure and Heartbeat - Driven Flexible Fiber Nanogenerators as a Micro/Nano - Power Source or Diagnostic Sensor," Advanced Materials, vol. 23, no. 1, pp. 84-89, 2011.

[153] H. Kim, Y. Kim, B. Kim et al., "A wearable fabric computer by planar-fashionable circuit board technique." pp. 282-285.

[154] J. Yoo, L. Yan, S. Lee et al., "A wearable ECG acquisition system with compact planar-fashionable circuit board-based shirt," IEEE Transactions on Information Technology in Biomedicine, vol. 13, no. 6, pp. 897-902, 2009.

[155] W.-Y. Chang, T.-H. Fang, and Y.-C. Lin, "Characterization and fabrication of wireless flexible physiological monitor sensor," Sensors and Actuators A: Physical, vol. 143, no. 2, pp. 196-203, 2008.

[156] H. Kim, Y. Kim, Y.-S. Kwon et al., "A $1.12 \mathrm{~mW}$ continuous healthcare monitor chip integrated on a planar fashionable circuit board." pp. 150-603.

[157] J. Yoo, L. Yan, S. Lee et al., "A $5.2 \mathrm{mw}$ self-configured wearable body sensor network controller and a $12 \mathrm{w}$ wirelessly powered sensor for a continuous health monitoring system," Solid-State Circuits, IEEE Journal of, vol. 45, no. 1, pp. 178$188,2010$.

[158] A. Colombo, D. Fontanelli, D. Macii et al., "Flexible indoor localization and tracking based on a wearable platform and sensor data fusion," IEEE Transactions on Instrumentation and Measurement, vol. 63, no. 4, pp. 864-876, 2014.

[159] M. Sibinski, M. Jakubowska, and M. Sloma, "Flexible temperature sensors on fibers," Sensors, vol. 10, no. 9, pp. 7934-7946, 2010

[160] W. Gao, S. Emaminejad, H. Y. Y. Nyein et al., "Fully integrated wearable sensor arrays for multiplexed in situ perspiration analysis," Nature, vol. 529, no. 7587, pp. 509-514, 2016.

[161] J. Liu, K. Song, P. A. van Aken et al., "Self-supported Li4Ti5O12-C nanotube arrays as high-rate and long-life anode materials for flexible Li-ion batteries," Nano letters, vol. 14, no. 5, pp. 2597-2603, 2014.

[162] A. M. Gaikwad, D. A. Steingart, T. Nga Ng et al., "A flexible high potential printed battery for powering printed electronics," Applied Physics Letters, vol. 102, no. 23, pp. 104_1, 2013.

[163] J. Ren, Y. Zhang, W. Bai et al., "Elastic and wearable wire - shaped lithium - ion battery with high electrochemical 
performance," Angewandte Chemie, vol. 126, no. 30, pp. 79988003, 2014.

[164] H. Gwon, J. Hong, H. Kim et al., "Recent progress on flexible lithium rechargeable batteries," Energy \& Environmental Science, vol. 7, no. 2, pp. 538-551, 2014.

[165] H. Wu, S. A. Shevlin, Q. Meng et al., "Flexible and Binder - Free Organic Cathode for High - Performance Lithium - Ion Batteries,” Advanced Materials, vol. 26, no. 20, pp. 3338-3343, 2014.

[166] C.-Y. Lee, S.-M. Chuang, S.-J. Lee et al., "Flexible micro sensor for in-situ monitoring temperature and voltage of coin cells," Sensors and Actuators A: Physical, vol. 232, pp. 214222, 2015.

[167] G. Zhou, F. Li, and H.-M. Cheng, "Progress in flexible lithium batteries and future prospects," Energy \& Environmental Science, vol. 7, no. 4, pp. 1307-1338, 2014.

[168] Y. Mao, G. Li, Y. Guo et al., "Foldable interpenetrated metalorganic frameworks/carbon nanotubes thin film for lithiumsulfur batteries," Nature Communications, vol. 8, 2017.

[169] K. Takei, W. Honda, S. Harada et al., "Toward Flexible and Wearable Human - Interactive Health - Monitoring Devices," Advanced healthcare materials, vol. 4, no. 4, pp. 487-500, 2015.

[170] Y.-L. Zheng, X.-R. Ding, C. C. Y. Poon et al., "Unobtrusive sensing and wearable devices for health informatics," IEEE Transactions on Biomedical Engineering, vol. 61, no. 5, pp. 1538-1554, 2014.

[171] S. Nayak, N. R. Blumenfeld, T. Laksanasopin et al., "Point-ofCare Diagnostics: Recent Developments in a Connected Age," Analytical Chemistry, 2016.

[172] Z. Bao, and X. Chen, "Flexible and Stretchable Devices," Advanced Materials, vol. 28, no. 22, pp. 4177-4179, 2016.

[173] T. F. O'Connor, S. Savagatrup, and D. J. Lipomi, "Soft Power: Stretchable and Ultra-Flexible Energy Sources for Wearable and Implantable Devices," Stretchable Bioelectronics for Medical Devices and Systems, pp. 69-82: Springer, 2016.

[174] F. Deng, H. Qiu, J. Chen et al., "Wearable Thermoelectric Power Generators Combined With Flexible Supercapacitor for Low-Power Human Diagnosis Devices," IEEE Transactions on Industrial Electronics, vol. 64, no. 2, pp. 1477-1485, 2017.

[175] T. Zhou, C. Zhang, C. B. Han et al., "Woven structured triboelectric nanogenerator for wearable devices," ACS applied materials \& interfaces, vol. 6, no. 16, pp. 14695-14701, 2014.

[176] D. Yamamoto, S. Nakata, K. Kanao et al., "All-printed, planartype multi-functional wearable flexible patch integrated with acceleration, temperature, and ECG sensors." pp. 239-242.

[177] X.-R. Ding, J. Liu, N. Zhao et al., "Cardiovascular Health Informatics: Wearable Medical Device and Flexible Biosensor for m-Health," Newsletter, vol. 2016, 2016.

[178] S. Wang, T. Chinnasamy, M. A. Lifson et al., "Flexible substrate-based devices for point-of-care diagnostics," Trends in Biotechnology, vol. 34, no. 11, pp. 909-921, 2016.

[179] A. Gangopadhyay, B. J. Nablo, M. V. Rao et al., "Flexible Thin - Film Electrodes on Porous Polyester Membranes for Wearable Sensors," Advanced Engineering Materials, vol. 19, no. $1,2017$.

[180] P. Bagade, A. Banerjee, and S. K. Gupta, "Evidence-based development approach for safe, sustainable and secure mobile medical app," Wearable Electronics Sensors, pp. 135-174: Springer, 2015.

[181] A. Dodabalapur, "Welcome to Flexible and Printed Electronics," Flexible and Printed Electronics, vol. 1, no. 1, pp. 010201, 2016

[182] E. Cantatore, Applications of organic and printed electronics: Springer, 2013.

[183] O. Bubnova, "Printed electronics: Nanotube resolution," Nature Nanotechnology, 2017.

[184] J. S. Chang, A. F. Facchetti, and R. Reuss, "Guest Editorial Organic/Printed Electronics: A Circuits and Systems Perspective," IEEE Journal on Emerging and Selected Topics in Circuits and Systems, vol. 7, no. 1, pp. 1-6, 2017.
[185] J. A. Lewis, and B. Y. Ahn, "Device fabrication: Threedimensional printed electronics," Nature, vol. 518, no. 7537, pp. 42-43, 2015.

[186] M. Stoppa, and A. Chiolerio, "Wearable electronics and smart textiles: a critical review," Sensors, vol. 14, no. 7, pp. 1195711992, 2014.

[187] K. Suganuma, Introduction to printed electronics: Springer Science \& Business Media, 2014.

[188] S. Zhang, S. Li, S. Cheng et al., "Research on smart sensing RFID tags under flexible substrates in printed electronics." pp. 1006-1009.

[189] C. Yeom, K. Chen, D. Kiriya et al., "Large - Area Compliant Tactile Sensors Using Printed Carbon Nanotube Active - Matrix Backplanes,” Advanced Materials, vol. 27, no. 9, pp. 1561-1566, 2015

[190] M.-U. Hassan, J. Keck, H. Klauk et al., "Combining organic and printed electronics in Hybrid System in Foil (HySiF) based smart skin for robotic applications." pp. 1-6.

[191] "Flexible Smart Sensors and the Future of Health," https://www.engadget.com/2015/09/21/flexible-smart-sensorsand-the-future-of-health/. Last accessed on 15.05.2017.

[192] "The State of Flexible and Printed Electronics," http://www.printedelectronicsnow.com/issues/2015-0301/view_features/the-state-of-flexible-and-printed-electronics. Last accessed on 15.05.2017.

[193] "2016-2026: Market Forecasts," http://www.idtechex.com/research/reports/wearable-sensors2016-2026-market-forecasts-technologies-players-000470.asp. Last accessed on 15.05.2017.

[194] "The Wearable Technology Ecosystem: 2016 - 2030 Opportunities, Challenges, Strategies, Industry Verticals And Forecasts," http://www.openpr.com/news/348933/TheWearable-Technology-Ecosystem-2016-2030-OpportunitiesChallenges-Strategies-Industry-Verticals-AndForecasts.html?_hstc=197865264.638cea001f4f55aadbd731e5 28921f0a.1482980112036.1482980112036.1482980112036.1\& hssc $=197865264.1 .1482980112037 \&$ hsfp $=1381054282$.

Last accessed on 15.05.2017.

[195] "Organic Electronics Will Play a Key Role in Increasing the Utility of Wearables," https://www.wearabletechnologies.com/2016/03/organic-electronics-will-play-a-keyrole-in-increasing-the-utility-of-wearables/. Last accessed on 15.05.2017. 